\title{
The Role of Physical Activities in Women Well Being
}

\author{
Ouelhezi Samira' ${ }^{1,2}$, Jelleli Hilmi1,3 \\ ${ }^{1}$ Higher Institute of Sport and Physical Education Kef, The Campus University of Boulifa, Boulifa, Tunisia \\ ${ }^{2}$ Research, Sportive performance \& Physical Rehabilitation "S2PR" (UR13JS01) \\ ${ }^{3}$ Laboratory of Clinical Psychology: Inter-Subjectivity and Culture, Tunis, Tunisia \\ Email: h.jelleli@gmail.com
}

How to cite this paper: Samira, O., \& Hilmi, J. (2017). The Role of Physical Activities in Women Well Being. Creative Education, 8, 2325-2331.

https://doi.org/10.4236/ce.2017.814159

Received: August 5, 2017

Accepted: November 26, 2017

Published: November 29, 2017

Copyright $\odot 2017$ by authors and Scientific Research Publishing Inc. This work is licensed under the Creative Commons Attribution International License (CC BY 4.0).

http://creativecommons.org/licenses/by/4.0/

\begin{abstract}
Regular physical activity is a source of fulfillment and emancipation for women on all levels. It is a factor of well-being that allows the woman to be in shape to assume its social responsibilities. Sport allows the woman to be more confident in increasing her self-esteem. This facilitates social integration in its surroundings. Such a state of total and complete equilibrium is beneficial to the whole of society.
\end{abstract}

\section{Keywords}

Physical Activities, Women, Well Being

\section{Introduction}

The history of women's sport is marked by gender-based discrimination. Health research suggests that women derive many health benefits from an active lifestyle (Oglesby, 2006). Women's access to sport, whether competitive or for welfare, has experienced social constraints and stereotypes of inequality between men and women. In this research, we will try to identify, in the first place, the positive impact of the sport practice on the state of health of the woman as well as on her physical beauty. Then, we focus on the psychological benefits of regular physical activity for women. We will end up with the role of sport in the social integration of women. Our objective is extricating the impact of physical exercise on women's life and updates the importance of sport's practice on her florescence and her development.

\section{Research Method}

A protocol interview is administrated with 11 different women as part of our 
sample. This protocol is composed of two parts. The first part concerns the reasons behind women's orientation towards practicing sports. The second part concerns the beneficial aspect of physical practice on women's quality of life. The interview is made in a manner that, in one hand, to compare the different responses through asking the same question to all interviewed persons and on the other hand to take into consideration the particularities of each subject (Kaufman, 1996).

- Modalities of the studied subject

From the beginning, we have informed women about our task and the objective behind. A semi-directive interview guide is prepared in advance and contains questions on the different topics to be discussed with the interviewees. The guide evolves during the survey and the questions are not asked in the same way or in the same order to all women. Before each interview, a review of the previous interviews is done in order to note the new points raised by the respondents to rephrase new questions. This makes the guide a benchmark for directing the inquiry in the desired direction and encourages the production of a speech by the interviewee (Blanchet et al., 1993). All interviews were conducted in sports halls before or after a training session and lasted between 30 and 40 minutes.

- Sample

The sample of a qualitative research by a semi-directive interview is generally smaller in size than that of quantitative research just relying on a questionnaire, because the collected data that one based on semi-directive interviews "are valued by context and they do not need to be according to their occurrence probability; only one given information through interview may have a weight which is equivalent to a repeated one (information) in questionnaire" (Kaufman, 1996).

Thus the determination of the sample size does not control statistical representativeness, but it is tributary of the exploitation given type. Based on the most possible exhaustive analysis, all the questions on open and formulated in a way to orient or to direct the interveners and to create a discussion and an interaction between the investigator and the investigated. Our empirical work is based on these principles. In our approach, we have interviewed eleven women that are practicing physical activities, almost in a regular way. They attend gyms and they are not chosen according to specific criteria, they belong to different social environments and they differ in age (From 24 to 56).

\section{Result}

- Women physical florescence through sport:

Modern woman leads a very busy life and a lot of social and family responsibilities. Her health is continuously assaulted. Her rhythm of life is more and more unbalanced and agitated. She is under a continuous pressure. All these aspects result in health deterioration.

Family duties, children, house work and the job are also dangers that woman 
is exposed to more than others. From here on, sport appears like one of the preferred means to fight against these harmful aspects of modern life and of society too. Sports culture is indeed excellent to both a young girl or simply to women (Saint-Martin \& Terret, 2004) women may therefore recourse to physical activities in order to distract themselves or to be flourish.

A great percentage of women are practicing physical activities to maintain their health and beauty of their bodies. Moufida is a married women, she is 48 years old, a nurse and a mother of 3 children. She suffers a high blood pressure. In order to manage her disease, she practices sport regularly. Her doctor advises her to do so. She admits that since she has begun doing sports, her health state is improved so much and she feels healthier. Mariem, a single 27 years old woman,a staff member in a company. She has been practicing sport for three years to diminish her weight and to reduce obesity. She said that: "since I have started doing sports, I lost many kilos and gained a lot of satisfaction". Sport is an excellent means to maintain a good health and to ameliorate physical shape to all the investigated women and you can listen phrases or statements like; "I feel better after a sport session", "with training I feel less fatigue when I do house chores", "I do not suffer from the pain that I had had everywhere before I started doing sports regularly", "I lost many kilos that made me suffer and I feel good about myself".

These ideas are, in fact, affirmed by health specialists who support that practising sport is an essential factor in health acquisition and maintenance. (INSERM), a team of researchers at Gustave-Roussy institute demonstrated in a recent study that Breast Cancer among women diminishes from 30\% to 38\% and that depending on intensity, regularity of sports practice duration; the regular practice of a physical activity allows the functioning integrity of vital functions of the organism (Doutreloux, 2004).

Christopher Delong: a specialist in re-education and a member in the French Association of Medicine and Sport traumatology affirms that: sport is beneficial to cardio-vascular system that it diminishes arterial tension and the risk of myocardial infraction and it increases and strengthens heart endurance (Delong, 2007). Ahlem, a doctor and a married 37 year old woman with two children devotes the necessary time to practice sport as any other daily life commitments. Ahlem started doing sports when she discovered that she suffers a bad cholesterol surplus. She admitted: "practicing sports regularly helps me be able to fight my disease without any recourse to medicaments. Now I suffer nothing". This idea is confirmed by Mouna, a young woman aged 34 and mother of a child who says: "After the birth, I had a problem on the back and I took weight. I became obese. With the practice of sport, I found my thin waist and I have more backache". Meanwhile, 54-year-old, Mounira added: "Since I started the sport, I no longer need to take painkillers for osteoarthritis of which I was suffering".

- Sports aesthetic function to woman

The first interest of woman is to acquire, to increase, to look for and to preserve beauty that it is the most powerful and available weapon to her in the incessant 
duel of sexes where woman plays freely the core of her happiness (Desbonnet, 1911). So to maintain her body is a legitimate behavior of woman. Imene, a young 26 tear old women employed as an accountant in a private company. She has been practicing sports for many years now. She declared that; "I do sports to be beautiful and to attract more my fiancée". Aida, a 38 year old teacher practices sports to keep her body slim and beautiful. "I do sport to be flexible". And that could not be achieved without recoursing to sports methods and hard work. Mounira said: "when I do sport, I find my body beautiful and I feel a satisfaction". Physical activity can offer particular qualities to woman efforts. Practicing sport in a regular way is only path for "the well-being" and the "be in form" of woman which become basic dimensions of feminine beauty such as grace, flexibility and slenderness. By instance, there is no woman that would not like to be beautiful, charming, attractive and desired. This is a principal part of womanhood. Thereby physical activity stands as excellent means to improve physical shape and ameliorates feminine corporal qualities. Sports forge ideal woman to seduce men (Louveau \& Davisse, 1998). Indeed, no one can deny, nowadays, that a state of well-being allows the woman to lead a long day well.

A good condition promotes woman to practice sport, but also to assure her social responsibilities which are based normally on physical

- Development through physical activity

Freud said: "the I is before all a corporal I" (Freud, 1991) which means that the self-esteem degree varies according to the individual satisfaction degree from his body. By this meaning so sports practice responds to the need to exercise, to movement and to physical outgoing can end in a feeling of satisfaction that guarantees psycho-physical balance of woman. Sport allows her to blossom up, to develop psychologically and to discharge aggressiveness. It is also a source of pleasure and enjoyment.

\subsection{Coping with Stress through Sport}

Sport is known as an excellent means of entertainment which helps woman to discharge and to escape from the grip of labor and family tasks and to fight against boredom and stress. Meriem is a single 27 years old. She has been doing sport for three years. She feels better after each training session: "sport became a means to get rid of bad moments of the day, especially after eight hours in a bureau". Jihen considers that sport helps discharging and blossoming "since I have started doing sports, I have become more delighted and more lighting up and satisfied with myself; my relationships, my family and with my colleagues.

Sport contributes to the lighting up and helps evacuate daily tensions and helps be in total concentration. Hanen, married, she is 30 years old, considers that sport is a means of fluorescence and pleasure. She said "this pleasure is essential to ovoid stress, it is a session of relaxation". This idea is repeated by all the interviewee.

Mouna relaxes when she practices sport, she is unemployed that's why sport 
stands as a means of florescence and fighting stress. Sport can help a nervous and stressed woman to calm down and to relax. Moufida, as well as all others, feels comfortable after each training session because sport helps her forget all her problems and regains her mood. "I reconcile with myself through physical exercise".

\subsection{Social Benefits of Sport on Woman}

Regular practice of a physical activity allows woman to find new friends, to maintain close relationships and new social relationships and to communicate with other and be situated in her social environment. To practice a physical activity in group, gives the woman the occasion to make new meeting and consequently maintains some conversations and discussions which could become intimates over time. Sport proves to be a means of socialization. Communication is a double-face coin. First to be in a relationship with someone and share common opinion and behaviors, second promotes interpersonal relationships.

Michel Bouet explains these sports functions saying that: "it seems that the central position of the lived corporality reconciles regularly those devoted to physical activities. It puts woman on the fundamental plan of legality. It reinforces the consciousness of 'for others' and of 'with others"' (Bouet, 1968).

Furthermore, physical activities induce a different link between the inside and the outside and introduce or present overlapping situations between public space and private space. Sport is considered as a means to access to more general social empowerment. Life outside the house is an open gate towards the extension. It is the conquest of a wide space than that of the family work and that of house. Sport is seen as a window towards environment "sport is an opining towards the outside". It is based on common life and the fight against self-confinement.

By instance, Dr Christopher Delong explains, in his book "le sport dans la vie d'une femme" the positive impact of physical activities on woman's health and consequently on social relationships nature. He also demonstrates that the medical and the social aspect of living are inseparable when it concerns woman wellbeing. Sports practice promotes interpersonal relationships and collective life. For woman, sport activity is not only an occasion to communicate with other but also a space of liberation. Hanan, married, was a 30 year old mother of two children affirms that: "during sport session, I know many women, we became friends, I discover that we have common concerns". It's the same idea sustained by mariem that she said: "I made a lot of friends due to sport, I mainly changed some characteristics since I have started practicing sport, I used to be very reserved. Now, I do not have a problem of integrity." Many of the investigated women raise the role of sport as a means to facilitate communication and to open the inter-individual dialogue. Jihen declares that: "I am a house wife, I practice sport to communicate, I discovered many sides in other woman's lives when compared to mine. I find some common points which make us closer". 
Halima, a single, is 27 years old; she has been practicing sport for a long time said: "sport is the only one means to ensure a life in group for me and for other woman in general". Whatever the age, sport encourages life in group and leads woman to develop her feelings of belonging which makes clear that woman need to be situated in society. All the women interviewed confirmed that the regular practice of sport has allowed them to better integrate into their social environment.

\section{Conclusion}

Sport provides woman with good health and a physical well-being. It helps her to be in form. It helps her fight diseases. Sport endows woman with a health and a force which makes her apt to fill in social duties that are waiting for them (Milliat, 1968).

The results of our research confirm that the regular practice of a sports activity such as dance, gymnastics, aerobics, brisk walking, running or cycling is the path of "well-being" and the "being fit" of women.

This study showed that sport increases life expectancy. It is certain that it improves life quality and diminishes the consumption of chemicals. Psychologically speaking, sport restores woman's self-confidence, as shown in the interview with Zaineb, married, was a 45 year old mother of two children affirms this idea by saying: "I feel much better since I started to practice sports". All the interviewee confirmed that they feel less stressed, less angry and most importantly; they have more confidence in themselves and love themselves more and more. This state of mind facilitates social integration such as state of total and complete balance is beneficial to society in all. On the basis of this idea, woman constitutes the half of society and that they assume the responsibility of the other half.

Knowing the benefits of practicing sport for woman, is it possible to find a place to be devoted to sport practice? Works are still there, they need to be done but let woman the freedom to do sports for her personal pleasure and let us help her in social charges. It will be useful to rethink about the idea of "sport for all" and facilitate the access to sport centers and gyms all over the country and for all social categories because sport can encompass the whole body culture of a people (Risse, 1921).

\section{References}

Blanchet, A., Alain, G., Gotman, A., \& Leger, J.-M. (1993). The Interview in the Social Sciences. Listening, Speech and Meaning (p. 7). Paris: Dunod.

Bouet, M. (1968). Meaning of Sport (p. 67). University Editions, Paris.

Delong, C. (2007). Sport in a Woman's Life (p. 54). Health Collection, Paris: Le cherche midi.

Desbonnet (1911). To Become Beautiful and to Remain Beautiful. In Manual of Physical Culture of the Woman (p. 23). Paris: Berger-Levrault.

Doutreloux, J.-P. (2004). Physiology and Sport Biology. Paris: Vigot.

Freud, S. (1991). The Me and the I, Complete Works, XVI (1921-1923) (pp. 256-301). 
Paris: PUF.

Kaufman, J.-C. (1996). The Comprehensive Interview. Paris: Nathan.

Louveau, C., \& Davisse, A. (1998). Sport, School, Society: The Difference between the Sexes. Preface by Geneviève Fraisse, Edition l'Harmatan.

Milliat, A. (1986). Arnaud in the Military, the Schoolboy, the Gymnast (p. 81). Paris: PUF.

Oglesby, C. A. (2006). en collaboration avec le Groupe de travail international sur les femmes et le sport, the Inter-national Association of Physical Education for Women and Girls, le Conseil international pour l'éducation physique et la science du sport. Positive Embodiment: Contributions of Sport, Exercise and PhysicalRecreation to the Life-long Development of Girls and Women, exposé rédigé pour la Division de la promotion de la femme de l'Organisation des Nations Unies.

Risse, H. (1921). Sociology of Sport. Published in France at the PU of Rennes, France.

Saint-Martin, J.-P., \& Terret, T. (2004). The French Sport between the Wars (p. 136). Paris: L'harmattan. 